\title{
Perbandingan Pola Bentuk Sidik Bibir Antara Suku Asli Mentawai dan Suku Campuran Mentawai
}

Valerio Alfa Agung Wafisal Sakoikoi ${ }^{1}$, Nur Indrawati Lipoeto², Murniwati ${ }^{1}$

Korespondensi : murniwati; murniwati@dent.unand.ac.id Telp: +628116614415

\begin{abstract}
One of studies that plays a role in human identification in disaster and crime is forensic odontology. There are several methods of identification in forensic odontology, one of the alternative methods is cheiloscopy which is used to identify lip print pattern. Lip print pattern is identical in each person, lip print can identify gender and human race. Mentawai ethnic is a part of Proto-Melayu race which dominates Mentawai island district area. Familial relationship in Mentawai ethnic is patrilineal the tribe is derived from father's tribe. This study aimed to compare the shape of lip print pattern between Mentawai original ethnic and Mentawai mixed ethnic. This study is a descriptive study with cross-sectional approach. The samples in this study were 16 pairs of Mentawai ethnic and 16 pairs of mixed Mentawai ethnic, the sample were selected using purposive sampling method. Lip print in study models were marked using colour pen, and the shape pattern of lip prints were observed and measured according to Suzuki and Tsuchihashi classification. Results of this study showed that there are differences in the pattern of lip prints between Mentawai ethnic and mixed Mentawai ethnic. Mentawai ethnic has dominan type of lip prints is type I, type II, and type IV while mixed Mentawai ethnic has dominan type of lip prints is type IV, type I, dan type III. The conclusion is there is a difference pattern of lip prints due to racial factors.
\end{abstract}

Keywords: lip print pattern, cheiloscopy, forensic odontology, mentawai ethnic, mixed mentawai ethnic

Affiliasi penulis: ${ }^{1}$ Fakultas Kedokteran Gigi Universitas Andalas; ${ }^{2}$ Fakultas Kedokteran Universitas Andalas

\section{PENDAHULUAN}

Identifikasi forensik merupakan upaya seorang dokter maupun dokter gigi dalam membantu penyidik untuk menentukan identitas seseorang. Proses identifikasi ini sangat penting dilakukan untuk menentukan identitas setiap individu yang merupakan korban maupun pelaku yang ditinjau dari segi forensik. ${ }^{1}$ Penentuan identitas seseorang dalam proses penyelidikan ditingkat medis, peradilan atau hukum bila tidak tepat dapat berakibat fatal. ${ }^{2}$ Dalam penentuan identifikasi personal dapat dilakukan dengan dua metode identifikasi, yaitu identifikasi primer dan sekunder. Identifikasi primer meliputi pemeriksaan DNA, sidik jari dan gigi, sedangkan identifikasi sekunder meliputi pemeriksaan rambut, tanda lahir, jaringan parut, visual, wajah atau foto, properti, dan sidik bibir. ${ }^{3}$ Sidik jari sangat sering digunakan penyidik sehingga para pelaku kriminal sangat mudah menghapus jejak atau bukti setelah melakukan tindak kriminal. ${ }^{3}$ Dengan demikian perlu teknik berbeda seperti cheiloscopy atau sidik bibir. Cheiloscopy atau sidik bibir ini bersifat unik dan berbeda pada setiap individu seperti sidik jari. ${ }^{4}$ Permukaan bibir bagian luar memiliki elevasi maupun lekukan yang membentuk pola karakteristik tertentu yang disebut sidik bibir. 
Sidik bibir ini merupakan gambaran alur pada mukosa bibir atas dan bawah, dan oleh Suzuki dinamakan "figura linearum labiorum rubrorum". Sidik bibir manusia bersifat stabil dan tidak berubah walaupun bertambah usia. ${ }^{5}$

Beberapa riset telah membuktikan, bahwasanya pola sidik bibir ini dapat mengidentifikasi dengan tepat jenis kelamin dan bangsa seseorang. Berdasarkan klasifikasi Suzuki dan Tsuchihachi bentuk alur pola bibir diklasifikasikan menjadi enam tipe, yaitu tipe vertikal lengkap, vertikal sebagian, bercabang, berpotongan, retikular, dan tidak beraturan. Pola garis vertikal lebih umum ditemukan pada perempuan dan pola berpotongan lebih banyak ditemukan pada laki-laki. ${ }^{6}$ Dari hasil penelitian Suzuki dan Tsuchihashi mengenai pola sidik bibir dalam kaitannya dengan bangsa, dinyatakan bahwa adanya perbedaan signifikan antara bangsa Melayu, Cina, dan India. ${ }^{7}$

Suku bangsa adalah suatu golongan manusia yang terikat oleh kesadaran dan identitas akan kesatuan kebudayaan. Kesadaran dan identitas tersebut diperkuat akan kesatuan bahasa yang digunakan, serta dengan kesatuan kebudayaan yang timbul karena suatu ciri khas dari suku bangsa itu sendiri bukan karena pengaruh dari luar. ${ }^{8}$

Ras India memiliki sidik bibir menurut klasifikasi Suzuki dan Tsuchihashi yaitu, tipe I, II, V. Kebangsaan India memiliki empat suku besar yaitu, Hindu, Dravida, Mongol dan Munda. ${ }^{9}$ Ras Melayu dibagi atas dua ras yaitu, Proto Melayu (melayu tua) dan Deutro Melayu (melayu muda). Proto Melayu migrasi ke Indonesia sekitar tahun 3000SM. Rumpun proto melayu berasal dari Asia yaitu daerah Yunan yang terletak di Cina Selatan. Mereka memasuki wilayah nusantara melalui dua jalur yaitu, jalur barat melalui Malaysia-Sumatra dan jalur utara melalui Philipina-Sulawesi. ${ }^{10}$ Ras Proto Melayu memiliki sidik bibir dominan tipe I, II, IV menurut klasifikasi Suzuki dan Tsuchihashi. ${ }^{9}$ Yang termasuk kedalam Proto Melayu adalah suku dayak, toraja, nias, mentawai. Deutro Melayu merupakan orang-orang Austronesia yang datang pada gelombang kedua. Suku yang termasuk ras Deutro Melayu adalah suku minang, melayu, sunda, bugis, jawa. ${ }^{10}$ Sidik bibir suku Minang yang merupakan ras Deutro Melayu dominan tipe I', II, I menurut klasifikasi Suzuki dan Tsuchihashi. ${ }^{9}$

Suku Mentawai termasuk golongan ras Proto Melayu, yang mendiami kepulauan Mentawai. Mentawai merupakan kepulauan yang ditemukan di lepas pantai barat Sumatera (Indonesia) yang terdiri dari sekitar 70 pulau. Empat pulau utama adalah Pagai Utara dan Pagai Selatan, Sipora, dan Siberut, dengan Siberut mencakup 4.480 kilometer persegi dan dengan jumlah penduduk sekitar 29.918 jiwa. Jumlah penduduk Kabupaten Kepulauan Mentawai mencapai 81.840 jiwa. ${ }^{11}$ Hubungan kekerabatan suku Mentawai adalah berdasarkan dari keturunan ayah. ${ }^{12}$ Di pulau Pagai Utara dan Pagai Selatan terdapat banyak suku bukan Mentawai dan bahkan menjalin pernikahan dengan suku Mentawai. ${ }^{13}$ Mereka berasal dari suku Minang, suku Batak, suku Flores, suku Nias, suku Jawa dan lain-lain. ${ }^{13}$

Berdasarkan latar belakang dan pengamatan peneliti belum ada penelitian yang menggambarkan pola sidik bibir pada suku Mentawai dan suku campuran Mentawai. Peneliti tertarik melakukan penelitian untuk mendeskripsikan gambaran pola bentuk sidik bibir suku asli Mentawai dan suku campuran Mentawai dengan menggunakan klasifikasi menurut Suzuki dan Tsuchihashi. 


\section{METODE}

Jenis rancangan penelitian ini adalah penelitian deskriptif dengan pendekatan cross sectional yaitu untuk mendeskripsikan gambaran pola bentuk sidik bibir suku asli Mentawai dan suku campuran Mentawai. Lokasi untuk penelitian adalah desa Matobe, Kecamatan Sikakap, Kabupaten Kepulauan Mentawai. Desa Matobe memiliki 11 Dusun yaitu, dusun Panataran, dusun Cempungan, dusun Tunang, dusun Makilat, dusun Mangaungau, dusun Bubuakat, dusun Polaga, dusun Ta'monga, dusun Sarere, dusun Makukuet, dusun Keleu. Penelitian dilakukan pada bulan November

Populasi penelitian ini adalah masyarakat Desa Matobe, Kabupaten Kepulauan Mentawai.

Sampel dihitung dengan rumus Sastroasmoro dan Ismael:

$\mathrm{n}_{1}=\mathrm{n}_{2}=2\left[\frac{(\mathrm{Z} \alpha+\mathrm{z} \beta) \mathrm{s}}{\left(\mathrm{x}_{1}-\mathrm{x}_{2}\right)}\right]^{2}$

di dapatkan jumlah sampel adalah 16 pasang sampel.

Teknik pengambilan sampel yang digunakan adalah Purposive sampling. Hal ini dilakukan dengan cara pengambilan sampel berdasarkan tujuan tertentu bukan berdasarkan strata dan random. Kriteria inklusi sampel yaitu masyarakat suku asli Mentawai dan suku campuran Mentawai. Kriteria eksklusi yaitu cleft lip, dan alergi lipstik.

Peneliti menentukan sampel melalui kriteria sampel inklusi dengan teknik purposive sampling. Pertama kali dilakukan wawancara dan pemeriksaan klinis bibir responden untuk mengetahui karakterisitik responden sesuai dengan kriteria inklusi dan eksklusi penelitian. Kemudian responden diberi penjelasan mengenai penelitian yang dilakukan dan mengisi informed consent, lalu dilakukan pengambilan sidik bibir responden. Pola sidik bibir responden akan ditandai dengan pena berwarna untuk menentukan klasifikasi sidik bibir responden.

\section{HASIL DAN PEMBAHASAN}

Tabel 1. Distribusi Sampel Penelitian Berdasarkan Usia Suku Asli Mentawai

\begin{tabular}{ccc}
\hline Golongan Usia & Frekuensi (n) & Persen (\%) \\
\hline 10-15 Tahun & 7 & 21,9 \\
16-20 Tahun & 12 & 37,5 \\
21-25 Tahun & 5 & 15,6 \\
26-30 Tahun & 5 & 15,6 \\
31-35 Tahun & 3 & 9,4 \\
Total & 32 & 100 \\
\hline
\end{tabular}

Tabel di atas merupakan distribusi sampel pada penelitian berdasarkan usia suku asli Mentawai. Usia 16-20 Tahun sebanyak 12 orang $(37,5 \%)$ dan merupakan jumlah terbanyak dari rentang usia lain. 
ANDalas dental jOURNAL

Fakultas Kedokteran Gigi Universitas Andalas

Jalan Perintis Kemerdekaan No. 77 Padang, Sumatera Barat

Web: adj.fkg.unand.ac.id Email: adj@dent.unand.ac.id

Tabel 2. Distribusi Sampel Penelitian Berdasarkan Usia Suku Campuran Mentawai

\begin{tabular}{ccc}
\hline Golongan Usia & Frekuensi (n) & Persen (\%) \\
\hline 10-15 Tahun & 7 & 21,9 \\
16-20 Tahun & 10 & 31,1 \\
21-25 Tahun & 11 & 34,4 \\
26-30 Tahun & 3 & 9,4 \\
31-35 Tahun & 1 & 3,1 \\
Total & 32 & 100 \\
\hline
\end{tabular}

Tabel di atas merupakan distribusi sampel pada penelitian berdasarkan usia suku campuran Mentawai. Usia 21-25 Tahun sebanyak 11 orang $(34,4 \%)$ dan merupakan jumlah terbanyak dari rentang usia lain.

Tabel 3. Distribusi Sampel Penelitian Laki-laki Suku Asli Mentawai

\begin{tabular}{|c|c|c|}
\hline Klasifikasi & Frekuensi (n) & Persen (\%) \\
\hline Tipe I & 10 & 62,5 \\
\hline Tipe I' & 0 & 0 \\
\hline Tipe II & 3 & 18,8 \\
\hline Tipe III & 0 & 0 \\
\hline Tipe IV & 1 & 6,3 \\
\hline Tipe V & 2 & 12,5 \\
\hline Total & 16 & 100 \\
\hline
\end{tabular}

Berdasarkan tabel di atas pola dominan sidik bibir adalah tipe I sebanyak 10 sampel (62,5\%), sedangkan sidik bibir tipe l' dan tipe III tidak ditemukan pada laki-laki suku asli Mentawai

Tabel 4. Distribusi Sampel Penelitian Laki-laki Suku Campuran Mentawai

\begin{tabular}{|c|c|c|}
\hline Klasifikasi & Frekuensi (n) & Persen (\%) \\
\hline Tipe I & 4 & 25,0 \\
\hline Tipe I' & 1 & 6,3 \\
\hline Tipe II & 5 & 31,3 \\
\hline Tipe III & 2 & 12,5 \\
\hline Tipe IV & 3 & 18,8 \\
\hline Tipe V & 1 & 6,3 \\
\hline Total & 16 & 100 \\
\hline
\end{tabular}

Tabel 4 memperlihatkan bahwa pola sidik bibir dominan adalah tipe II sebanyak 5 sampel (31,3\%). Pola sidik bibir tipe I' dan tipe $\vee$ hanya sebanyak 1 sampel $(6,3 \%)$ dan merupakan pola sidik bibir paling sedikit. 
ANDALAS DENTAL JOURNAL

Fakultas Kedokteran Gigi Universitas Andalas

Jalan Perintis Kemerdekaan No. 77 Padang, Sumatera Barat

Web: adj.fkg.unand.ac.id Email: adj@dent.unand.ac.id

Tabel 5. Distribusi Sampel Penelitian Perempuan Suku Asli Mentawai

\begin{tabular}{|c|c|c|}
\hline Klasifikasi & Frekuensi (n) & Persen (\%) \\
\hline Tipe I & 10 & 62,5 \\
\hline Tipe I' & 0 & 0 \\
\hline Tipe II & 2 & 12,5 \\
\hline Tipe III & 1 & 6,3 \\
\hline Tipe IV & 3 & 18,8 \\
\hline Tipe V & 0 & 0 \\
\hline Total & 16 & 100 \\
\hline
\end{tabular}

Berdasarkan tabel di atas pola dominan sidik bibir adalah tipe I sebanyak 10 sampel (62,5\%), sedangkan sidik bibir tipe I' dan tipe $\mathrm{V}$ tidak ditemukan pada perempuan suku asli Mentawai.

Tabel 6. Distribusi Sampel Penelitian Perempuan Suku Campuran Mentawai

\begin{tabular}{|c|c|c|}
\hline Klasifikasi & Frekuensi (n) & Persen (\%) \\
\hline Tipe I & 4 & 25,0 \\
\hline Tipe I' & 0 & 0 \\
\hline Tipe II & 2 & 12,5 \\
\hline Tipe III & 3 & 18,8 \\
\hline Tipe IV & 5 & 31,3 \\
\hline Tipe V & 2 & 12,5 \\
\hline Total & 16 & 100 \\
\hline
\end{tabular}

Berdasarkan tabel di atas pola dominan sidik bibir adalah tipe IV sebanyak 5 sampel $(31,3 \%)$, sedangkan sidik bibir tipe l' tidak ditemukan pada perempuan suku campuran Mentawai.

\section{Pola Sidik Bibir Suku Asli Mentawai}

Dalam penelitian ini pola sidik bibir suku asli Mentawai (Proto-Melayu) yang dominan adalah Tipe I (Vertical Groove). Penelitian ini tidak sejalan dengan penelitian Yuni Kardisa (2016) dan mendapat sidik bibir dominan ras melayu adalah tipe IV. ${ }^{14} \mathrm{Hal}$ ini berbeda dengan penelitian Vivek Sharma terhadap 200 mahasiswa di India pada tahun 2014, pola sidik bibir paling dominan adalah Type III. ${ }^{15}$ Pola sidik bibir dapat membedakan ras seseorang. Pola sidik bibir sangat unik dan identik antar individu. ${ }^{16} \mathrm{Qomariah}$ dkk (2016) di Fakultas Kedokteran Gigi Jember yang dilakukan pada 80 sampel mahasiswa menggunakan metode lipstik. Pada etnis Melayu pola sidik bibir yang paling dominan adalah tipe I' (Parsial Vertical Groove), sedangkan pada etnis China dan India pola sidik bibir yang dominan adalah tipe I (Vertical Groove). ${ }^{17}$ Penelitian Qomariah bertolak belakang dengan penelitian ini dimana Qomariah mendapatkan sidik bibir dominan ras Melayu adalah tipe I' sedangkan peneliti mendapatkan tipe I. ${ }^{17}$

Ninad Nagrale dkk melakukan penelitian terhadap ras India dengan jumlah sampel 500 orang. Pola sidik bibir pada laki-laki ras India didominasi oleh tipe III (Intersected Groove) dan pada wanita ras India didominasi oleh tipe II (Branched Groove). ${ }^{18}$ Ninad Nagrale mendapatkan hasil yang bertolak 
belakang dengan peneliti, dimana Ninad Nagrale mendapatkan hasil untuk laki-laki ras India didominasi oleh tipe III dan perempuan tipe II, sedangkan peneliti menyatakan tipe I adalah tipe dominan untuk lakilaki dan perempuan. ${ }^{18} \mathrm{Hal}$ ini mendukung penelitian Prabhu pada tahun 2012 bahwa tidak terdapat hubungan antar pola sidik bibir dengan jenis kelamin, karena kedua jenis kelamin memiliki tipe dominan yang sama. ${ }^{19}$

\section{Pola Sidik Bibir Suku Campuran Mentawai}

Dari hasil penelitian pola sidik bibir suku campuran mentawai, peneliti mendapatkan perbedaan antara sidik bibir laki-laki dan perempuan. Pola sidik bibir paling dominan untuk laki-laki adalah tipe II dan perempuan tipe IV. Penelitian ini tidak sejalan dengan penelitian Qomariah (2016) di Jember dimana tipe III lebih dominan untuk laki-laki dan tipe l' untuk perempuan. ${ }^{15}$ Pola sidik bibir tidak ada yang sama dan dapat dipengaruhi oleh variasi ras. ${ }^{20}$ Penelitian pola sidik bibir oleh $\mathrm{Xu}$ pada populasi Universitas Kebangsaan Malaysia dimana tipe l' adalah pola sidik bibir yang dominan pada etnis Melayu, sedangkan tipe I adalah pola sidik bibir paling dominan etnis India dan China. ${ }^{21}$

Pada penelitian Dedi Afandi (2017) pola sidik bibir tipe II dominan pada suku asli Melayu Riau dan suku bukan Melayu Riau. ${ }^{22} \mathrm{Hal}$ ini tidak sejalan dengan hasil penelitian ini. Faktor ini dapat terjadi karena pola sidik bibir juga dapat dipengaruhi oleh faktor keturunan (genetik). ${ }^{23}$

Menurut Thomas Hunt Morgan, gen merupakan materi yang kompak dan mengandung satuan informasi genetik yang mengatur sifat-sifat menurun, memenuhi suatu kromom. Gen mengatur berbagai macam karakter fisik maupun karakter psikis. ${ }^{24}$

\section{SIMPULAN}

Penelitian yang dilakukan pada 16 pasang cetakan sidik bibir suku asli Mentawai dan suku campuran Mentawai mendapatkan hasil sebagai berikut:

1. Pola sidik bibir dominan suku asli Mentawai adalah tipe I dan diikuti tipe II dan tipe IV, sedang pola sidik bibir dominan suku campuran adalah tipe IV dan diikuti tipe I dan tipe III. Sidik bibir laki-laki suku asli Mentawai didominasi tipe I,II,V sedangkan laki-laki suku campuran Mentawai didominasi tipe II, I, IV. Sidik bibir perempuan suku asli Mentawai didominasi tipe I, IV, II sedang perempuan suku campuran didominasi tipe IV, I, III.

2. Pola dominan yang memiliki kesamaan antar sidik bibir suku asli Mentawai dengan suku campuran Mentawai adalah tipe I dan tipe IV. Pola yang membedakan sidik bibir antara suku asli Mentawai dan suku campuran Mentawai adalah pola sidik bibir tipe II terdapat pada suku asli Mentawai sedangkan pola tipe III terdapat pada suku campuran Mentawai.

\section{KEPUSTAKAAN}

1. Reddy LVK. Lip prints : an overview in forensic denstistry. J. Adv Dental Research, 2011; II: 17-20.

2. Amir, Amri. Ilmu Kedokteran Forensik. Medan : Bagian IImu Kedokteran Forensik dan Medikolegal Fakultas Kedokteran USU. 2007. 
3. Suryadi, Taufik. Pengantar IImu Kedokteran Forensik dan Medikolegal Buku Penuntun Kepaniteraan Klinik Kedokteran Forensik dan Medikolegal. Banda Aceh : FK Unsyiah. 2009.

4. Eroschenko VP., diFiore's atlas of histology with functional corrections. Jakarta : EGC, 2003, pp. 148.

5. Domiatry M.A.E., et al., Morphological patterns of lip prints in Saudi Arabia at Almasinah Almonawwaroh province. J For Sci Int 2010; 200: 179.e1 - 179.e9.

6. Vahanwala S, Nayak C, Pagar S. Study of Lip Prints as Aid for Sex Identification. Medico-legal update, 2005; 5: 93-8.

7. Xu NX, et al., Lip Prints in Sex and Race determination. Jurnal sains Kesihatan Malaysia, 2012; 10(1): 29-33

8. Pusat Bahasa Depdiknas. Kamus Besar Bahasa Indonesia (edisi ketiga). Jakarta: Balai Pustaka. 2002.

9. TR Saraswhati, Gauri Mishra, K Ranganathan, Study of Lip Prints. J Forensic Dent Sci. 2009.

10. Reid, Anthony. "Understanding Malay as a Source of Diverse Modern Identities". Journal of Southeast Asian Studies. 2001.

11. Indriani. Mengenal Masyarakat Indonesia. CV. Chyyas Putra, 2010, pp. 4.

12. Spina, Bruno. Suku Mentawai. PN Balai Pustaka, 1981.

13. Hernawati, Tarida, Uma Fenomena Keterikatan Manusia Dengan Alam. Yayasan Citra Mandiri. 2007.

14. Kardisa, Yunni, Gambaran Tipe Sidik Bibir dan Jarak Interkomisura Suku Asli Gayo, Aceh dan Melayu Pada Mahasiswa Fakultas Kedokteran Gigi Universitas Syiah Kuala. Aceh: Universitas Syiah Kuala. 2016.

15. Sharma, Vivek, Identification Of Sex Using Lip Prints: A Clinical Study. India: Journal Of Internasional Society Of Preventive and Community Dentistry. 2014.

16. Malik R, Goel S., Cheiloscopy: A Deterministic Aid For Forensic Sex Determination. J Indian Acad Oral Med Radiol, 2011; 23: 9-17.

17. Qomariah, S., Hubungan Antara Pola Sidik Bibir dengan Jenis Kelamin Pada Mahasiswa Kedokteran Gigi Universitas Jember. E-Jurnal Pustaka Kesehatan, 2016: Vol. 4.

18. Septadina, Indri Seta, Identifikasi Individu dan Jenis Kelamin Berdasarkan Pola Sidik Bibir. Jurnal Kedokteran dan Kesehatan, 2015; 2(2): 231-236.

19. Ninad, Nagrale. Establishing Cheiloscopy As A Tool For Identic Action: An Assesment On 500 Subject In Central India Al Ameen J Med Sc I, 2014; 7 (3): 201-206.

20. Prabu R.V., Collection of lip prints as a forensic evidence at the crime scene-an insight. J Oral Health Research, 2012: Vol. 1(4).

21. Neo Xiao Xu, Lip Prints In Sex And Race Determination. Malaysia: Jurnal Sains Kesihatan Malaysia, 2012; 10(1): 29-33.

22. Afandi, Dedi, Hubungan Antara Pola Sidik Bibir dan Jenis Suku Melayu Riau. Riau. 2017.

23. Sharma, P., Cheiloscopy: The Study Of Lip Prints In Sex Identification. Journal Of Forensic Dental Sciences, 2009; 1(1): 24-27.

24. Suryo, Genetika Manusia. Cetakan 8, Yogyakarta: Gadjah Mada University Press. 2005. 